\title{
Preface
}

\section{3th European Symposium on Controlled Drug Delivery (ESCDD2014)}

The thirteenth edition of the European Symposium on Controlled Drug Delivery was held from April 16 to 18 at Hotel Zuiderduin in Egmond aan Zee, The Netherlands. Already since the start of the symposium series in 1990 by Drs Jan Feijen, Tom Sam, and Jorge Heller, the goal of this biennial symposium is to provide a leading European forum for researchers from academia and industry in the field of advanced drug delivery. In addition, the symposium intends to be an informal meeting place with strong interactions between leading scientists and young researchers in the field. Therefore, ample time is reserved during the symposium to meet each other for discussions and social activities are incorporated in the program to establish or tighten informal contacts.

Also for this edition the organizing committee has succeeded to compose a program of plenary lectures on cutting edge topics in drug delivery. Supported by suggestions from the Scientific Advisory Board, 26 international experts were invited, both renowned and young emerging scientists in their field, to present recent developments in sessions on multifunctional carriers for targeted delivery, nucleic acid delivery, particulate protein and vaccine delivery, bioactive delivery for tissue engineering, and extracellular and extracellular and intracellular interactions in drug delivery. The relation with industrial research was in focus in the session on drug delivery and the pharma market. Moreover, a special session was organized on image-guided drug delivery in cooperation with the work party of the EC-COST program on this topic.

The full symposium program can be found at www.escdd.eu and a good impression of the lectures can be obtained from the 19 papers that were generated from the presentations at the symposium and are included in this special issue of the Journal of Controlled Release.
The organizers like to thank the sponsors of this 13th edition of the symposium: Elsevier for sponsoring of the poster prizes and the MIRA Institute for Biomedical Technology of the University of Twente for financial support. Moreover, we wish to express our gratitude to the invaluable contributions to the success of the symposium by our colleagues in the organization committee, Jos Paulusse, Karin Hendriks, and Hetty ten Hoopen of the University of Twente, who have organized all logistic, financial and administrative issues, and Stefaan de Smedt together with his administrative staff members Catherine Wullaert and Ilse Dupon of the University of Ghent who have taken care for the appearance of an excellent abstract book including abstracts of all lectures and posters of the symposium.

Wim E. Hennink

Department of Pharmaceutics, Utrecht Institute for Pharmaceutical Sciences, Utrecht University, 3584 CG Utrecht, The Netherlands

Johan F.J. Engbersen

Department of Controlled Drug Delivery, MIRA Institute for Biomedical Technology and Technical Medicine, Faculty of Science and Technology, University of Twente, P.O. Box 217, 7500 AE Enschede, The Netherlands Corresponding author. Tel.: +31534892968. E-mail address: j.f.j.engbersen@utwente.nl. 